\title{
Aging of the Immune System: Research Challenges to Enhance the Health Span of Older Adults
}

\author{
Laura Haynes * \\ UConn Center on Aging, University of Connecticut School of Medicine, Farmington, CT, United States
}

Keywords: inflammaging, cellular senescence, health span, geroscience hypothesis, aging immune system

\section{OPEN ACCESS}

Edited and reviewed by: Anshu Agrawal, University of California, United States

*Correspondence: Laura Haynes Ihaynes@uchc.edu

Specialty section:

This article was submitted to Aging and the Immune System, a section of the journal

Frontiers in Aging

Received: 02 September 2020

Accepted: 14 September 2020

Published: 15 October 2020

Citation:

Haynes L (2020) Aging of the Immune

System: Research Challenges to

Enhance the Health Span of

Older Adults.

Front. Aging 1:602108.

doi: 10.3389/fragi.2020.602108
The world's population is aging, which brings about huge scientific challenges. Since the biological process of aging is by far the greatest risk factor for most chronic diseases, understanding the molecular and cellular mechanisms by which aging leads to these conditions is of vital importance to increase the health span of older adults.

One of the most prominent biological systems to face the impacts of aging is the immune system, with age-related changes in immunity being responsible for an increase in susceptibility to infectious diseases and a decrease in the effectiveness of vaccinations. In addition, the innate immune system is responsible for one of the main characteristics of aging, namely, the increase in low-grade inflammation known as inflammaging. Five research challenges present themselves: the origins and impact of age-related inflammation, the impact of senescence on immunity, age-related changes in immune function, the effects of decreased immune function on infection and vaccination, and strategies to overcome declining immunity. These are all especially important at this time, since aging is a major risk factor for the development of severe complications from infectious diseases such as COVID-19, influenza, and bacterial pneumonia.

\section{AGING AND INFLAMMATION (INFLAMMAGING)}

One of the main characteristics of aging is chronic activation of the immune system that results in low-grade inflammation which is mainly driven by macrophages (Franceschi et al., 2000). The agerelated mechanisms responsible for driving this inflammation include cellular senescence, mitochondrial dysfunction, defective autophagy, activation of the inflammasome, activation of the DNA damage response, changes in the composition of the microbiome, and chronic infections such as those caused by human cytomegalovirus (CMV) (Vitale et al., 2013; Pawelec, 2014; Heath and Grant, 2020). The mediators of this systemic inflammation are pro-inflammatory cytokines such as interleukin-6 and tumor necrosis factor alpha, which increase with increasing age (Bruunsgaard, 2006; Maggio et al., 2006). This chronic inflammation is a highly significant risk factor for both morbidity and mortality in older adults (Franceschi et al., 2000) and is hypothesized to be a driver of age-related diseases such as type 2 diabetes, Alzheimer's disease, atherosclerosis, osteoarthritis, cancer, and hypertension (Freund et al., 2010; Childs et al., 2017; He and Sharpless, 2017).

While researchers have gained a better understanding of inflammaging, other impacts of inflammaging remain to be explored, including its influence on adaptive immune responses such as vaccine-induced protective immunity, T-cell differentiation, and susceptibility to complications following respiratory infections such as COVID-19 and influenza. 


\section{SENESCENCE}

Cellular senescence is characterized by a state of essentially irreversible proliferative arrest caused by potentially oncogenic stressors and is now recognized as an important tumor suppression mechanism (Braig et al., 2005; Michaloglou et al., 2005; Collado and Serrano, 2010). Importantly, senescent cells secrete a myriad of factors which have been called the "senescenceassociated secretory phenotype" (SASP). The main goal of SASP production is to activate innate immune cells, such as macrophages, to clear the SASP-producing senescent cells by phagocytosis and, thus, prevent tumor development. The SASP includes growth factors, pro-inflammatory cytokines, chemokines, and proteases, all of which can contribute to inflammaging (Coppe et al., 2008; Freund et al., 2010). With increasing age, senescent cells are not cleared as efficiently by the innate immune system, causing them to accumulate and increasing SASP levels (Coppe et al., 2008; Zhu et al., 2014; Xu et al., 2018). Furthermore, senescent cell accumulation in fat also increases with aging, linking senescence to age-related changes in metabolism (Xu et al., 2015). Senescent cells and SASP have dramatic impacts on disease states, including loss of physical function, osteoarthritis, frailty, and loss of insulin sensitivity (LeBrasseur et al., 2015; Xu et al., 2015; Xu et al., 2018). Recent studies have shown that clearance of these senescent cells in transgenic mouse models or by senolytic drug treatment can alleviate senescence-associated disease states (Xu et al., 2015; Xu et al., 2018). In addition, a 2019 study has also shown that deletion of senescent cells enhances T-cell proliferation (Palacio et al., 2019).

Taken together, these studies are encouraging and support the geroscience hypothesis which states that most, if not all, agerelated chronic diseases can be alleviated by interventions that retard the aging process and/or senescence. Importantly, the precise role that senescence and SASP play in age-related changes in innate and adaptive immunity remains relatively unexplored and is a potentially important area of investigation.

\section{AGE-RELATED CHANGES IN THE IMMUNE RESPONSE}

While the impact of aging on both innate and adaptive immunity has been well documented, the mechanistic causes are not well understood. The age-related changes in immune function are most likely due to a combination of intrinsic cell aging and the impact of the senescent/aging environment on proliferation and differentiation in response to antigenic stimulation. In addition to age-related changes in cells of the immune system, there are changes in chemokine localization and the microarchitecture of both lymph nodes and spleen that can impact cell trafficking and encounters with cognate antigen (Thompson et al., 2017; Turner and Mabbott, 2017; Masters et al., 2018; Masters et al., 2019). Innate immune cells contribute to inflammaging by producing cytokines that are associated with chronic inflammation, but other important functions of innate immune cells such as phagocytosis, antigen uptake and presentation, migration, and bactericidal activity are diminished with aging (Henry et al., 2011). With regard to adaptive immunity, CD4 and CD8 T cells and B cells all show age-related changes in function. Due to early life thymic involution and a lifetime of antigenic exposure, memory phenotype T cells predominate in older individuals (Cossarizza et al., 1996; Linton and Dorshkind, 2004). Additionally, chronic infections such as CMV infections contribute to the accumulation of highly differentiated memory CD8 $\mathrm{T}$ cells that exhibit characteristics of replicative senescence (Ouyang et al., 2003; Pawelec and Gouttefangeas, 2006). The age-related accumulation of these terminally differentiated CD8 $\mathrm{T}$ cells serves to constrict the immune repertoire and has also been associated with the impaired immune response to vaccinations and novel infections, such as SARS-CoV-2, observed in older adults (Akbar and Fletcher, 2005; McElhaney et al., 2012). With regard to CD4 T cells, age-related changes in function include diminished proliferative capacity, inappropriate $\mathrm{T}$ helper subset differentiation, and an increase in the percentage of regulatory $\mathrm{T}$ cells (MoroGarcia et al., 2013; Lorenzo et al., 2018). B cell function is also significantly impacted by aging: several B-cell biomarkers of aging have been characterized and are related to reduced class-switch recombination and somatic hypermutation of immunoglobulin genes, which ultimately result in reduced antibody production and function following vaccination or infection (Blomberg and Frasca, 2013).

The mechanisms responsible for these age-related changes in both innate and adaptive immunity remain to be explored, and a more thorough understanding could help us devise better strategies to overcome them.

\section{HOW AGE-RELATED CHANGES IMPACT INFECTION AND VACCINATION}

Because of the abovementioned age-related changes in innate and adaptive immune function, older adults exhibit increased susceptibility to infections such as influenza, COVID-19, and bacterial pneumonia. Influenza is responsible for up to 500,000 deaths per year worldwide, with two-thirds of these occurring in adults over 65 years of age (Paget et al., 2019). Older adults are also more susceptible to COVID-19 and its complications (Nanda et al., 2020). In the U.S., $80 \%$ of COVID-19 deaths occur in people $>65$ years of age, and mortality rates for those $>80$ years of age can be as high as $50 \%$ (Powell et al., 2020). The incidence of bacterial pneumonia in adults in the U.S. $>65$ years of age is more than 4 times higher than that found in adults aged $<45$ years, and hospitalization rates for elderly patients is highest for the oldest groups (Henig and Kaye, 2017).

Not only are older adults more susceptible to these infections, but they are also more susceptible to complications during these infections, in part because of the many co-morbidities associated with increasing age (Keilich et al., 2019). Vaccinations are strongly recommended for older adults to protect them from both influenza and bacterial pneumonia, but because of agerelated changes in immune function, vaccine efficacy and effectiveness decline with age (Ciabattini et al., 2018). Further understanding of how aging of the immune system results in increased susceptibility to infectious diseases and decreased 
vaccine efficacy will contribute greatly to improving the health span of older adults.

\section{STRATEGIES TO OVERCOME AGE-RELATED CHANGES IN IMMUNITY}

Research continues to discover approaches to overcoming agerelated declines in immunity. Novel approaches to specifically target the immune system as well as geroscience-directed approaches, which target the underlying causes of aging, should provide us with exciting new therapies to extend the health span of older adults.

Several approaches are already in use or are undergoing testing. First, vaccines specifically formulated for older adults are now available and have been shown to provide greater protection from viral infections such as influenza. These vaccines have higher concentrations of antigen or are formulated with adjuvants to boost aging immune responses (McElhaney et al., 2020). Second, approaches that alter metabolism such as treatment with metformin (Barzilai et al., 2016) or mTOR inhibitors (Mannick et al., 2018) could help improve immunity and resistance to infectious diseases in older

\section{REFERENCES}

Akbar, A. N., and Fletcher, J. M. (2005). Memory T cell homeostasis and senescence during aging. Curr. Opin. Immunol. 17, 480-485. doi:10.1016/j.coi.2005.07.019

Barzilai, N., Crandall, J. P., Kritchevsky, S. B., and Espeland, M. A. (2016). Metformin as a tool to target aging. Cell Metab. 23, 1060-1065. doi:10.1016/ j.cmet.2016.05.011

Blomberg, B. B., and Frasca, D. (2013). Age effects on mouse and human B cells. Immunol. Res. 57, 354-360. doi:10.1007/s12026-013-8440-9

Braig, M., Lee, S., Loddenkemper, C., Rudolph, C., Peters, M., Schlegelberger, B., et al. (2005). Oncogene-induced senescence as an initial barrier in lymphoma development. Nature 436, 660-665. doi:10.1038/nature03841

Bruunsgaard, H. (2006). The clinical impact of systemic low-level inflammation in elderly populations. With special reference to cardiovascular disease, dementia and mortality. Dan. Med. Bull. 53, 285-309.

Childs, B. G., Gluscevic, M., Baker, D. J., Laberge, R.-M., Marquess, D., Dananberg, J., et al. (2017). Senescent cells: an emerging target for diseases of ageing. Nat. Rev. Drug Discov. 16, 718-735. doi:10.1038/nrd.2017.116

Ciabattini, A., Nardini, C., Santoro, F., Garagnani, P., Franceschi, C., and Medaglini, D. (2018). Vaccination in the elderly: the challenge of immune changes with aging. Semin. Immunol. 40, 83-94. doi:10.1016/j.smim.2018.10.010

Collado, M., and Serrano, M. (2010). Senescence in tumours: evidence from mice and humans. Nat. Rev. Canc. 10, 51-57. doi:10.1038/nrc2772

Coppe, J. P., Patil, C. K., Rodier, F., Sun, Y., Muñoz, D. P., Goldstein, J., et al. (2008). Senescence-associated secretory phenotypes reveal cell-nonautonomous functions of oncogenic RAS and the p53 tumor suppressor. PLoS Biol. 6, 2853-2868. doi:10.1371/journal.pbio.0060301

Cossarizza, A., Ortolani, C., Paganelli, R., Barbieri, D., Monti, D., Sansoniand, P., et al. (1996). CD45 isoforms expression on CD4+ and CD8+ T cells throughout life, from newborns to centenarians: implications for $\mathrm{T}$ cell memory. Mech. Ageing Dev. 86, 173-195. doi:10.1016/0047-6374(95)01691-0

Franceschi, C., Bonafè, M., Valensin, S., Olivieri, F., De Luca, M., Ottaviani, E., et al. (2000). Inflamm-aging. An evolutionary perspective on immunosenescence. Ann. N. Y. Acad. Sci. 908, 244-254. doi:10.1111/j.1749-6632.2000.tb06651.x

Freund, A., Orjalo, A. V., Desprez, P. Y., and Campisi, J. (2010). Inflammatory networks during cellular senescence: causes and consequences. Trends Mol. Med. 16, 238-246. doi:10.1016/j.molmed.2010.03.003 adults. Last, senolytics, which are a novel class of drugs that target the destruction of senescent cells, have been shown to alleviate age-related diseases in animal models and could possibly also improve aged immune function (Xu et al., 2018).

Continued research in this field will help discover other novel approaches which will help enhance and extend the life span of older adults.

\section{CONCLUSION}

Responding to the unanswered questions in the research challenges outlined, the aim of the specialty section Aging and the Immune System (part of Frontiers in Aging) is to contribute to the overall understanding of aging and immunity with a focus on the translational aspects that may improve human health span.

\section{AUTHOR CONTRIBUTIONS}

The author confirms being the sole contributor of this work and has approved it for publication.

He, S., and Sharpless, N. E. (2017). Senescence in health and disease. Cell 169, 1000-1011. doi:10.1016/j.cell.2017.05.015

Heath, J. J., and Grant, M. D. (2020). The immune response against human cytomegalovirus links cellular to systemic senescence. Cells 9, 766. doi:10.3390/ cells 9030766

Henig, O., and Kaye, K. S. (2017). Bacterial pneumonia in older adults. Infect. Dis. Clin. 31, 689-713. doi:10.1016/j.idc.2017.07.015

Henry, C. J., Marusyk, A., and DeGregori, J. (2011). Aging-associated changes in hematopoiesis and leukemogenesis: what's the connection? Aging 3, 643-656. doi:10.18632/aging.100351

Keilich, S. R., Bartley, J. M., and Haynes, L. (2019). Diminished immune responses with aging predispose older adults to common and uncommon influenza complications. Cell. Immunol. 345, 103992. doi:10.1016/j.cellimm.2019.103992

LeBrasseur, N. K., Tchkonia, T., and Kirkland, J. L. (2015). Cellular senescence and the biology of aging, disease, and frailty. Nestle Nutr. Inst. Workshop Ser. 83, 11-18. doi:10.1159/000382054

Linton, P. J., and Dorshkind, K. (2004). Age-related changes in lymphocyte development and function. Nat. Immunol. 5, 133-139. doi:10.1038/ni1033

Lorenzo, E. C., Bartley, J. M., and Haynes, L. (2018). The impact of aging on CD4(+) $\mathrm{T}$ cell responses to influenza infection. Biogerontology 19, 437-446. doi:10.1007/s10522-018-9754-8

Maggio, M., Guralnik, J. M., Longo, D. L., and Ferrucci, L. (2006). Interleukin-6 in aging and chronic disease: a magnificent pathway. J. Gerontol. Ser. A 61, 575-584. doi:10.1093/gerona/61.6.575

Mannick, J. B., Morris, M., Hockey, H.-U. P., Roma, G., Beibel, M., Kulmatycki, K., et al. (2018). TORC1 inhibition enhances immune function and reduces infections in the elderly. Sci. Transl. Med. 10. doi:10.1126/scitranslmed. aaq1564

Masters, A. R., Hall, A., Bartley, J. M., Keilich, S. R., Lorenzo, E. C., Jellison, E. R., et al. (2019). Assessment of lymph node stromal cells as an underlying factor in age-related immune impairment. J. Gerontol. Ser. A 74, 1734-1743. doi:10. 1093/gerona/glz029

Masters, A. R., Jellison, E. R., Puddington, L., Khanna, K. M., and Haynes, L. (2018). Attrition of $\mathrm{T}$ cell zone fibroblastic reticular cell number and function in aged spleens. Immunohorizons 2, 155-163. doi:10.4049/immunohorizons. 1700062

McElhaney, J. E., Zhou, X., Talbot, H. K., Soethout, E., Bleackley, R. C., Granville, D. J., et al. (2012). The unmet need in the elderly: how immunosenescence, CMV infection, 
co-morbidities and frailty are a challenge for the development of more effective influenza vaccines. Vaccine 30, 2060-2067. doi:10.1016/j.vaccine.2012.01.015

McElhaney, J. E., Andrew, M. K., Haynes, L., Kuchel, G. A., McNeil, S. A., Pawelec, $\mathrm{G}$, et al. (2020). Influenza vaccination: accelerating the process for new vaccine development in older adults. Interdiscip. Top. Gerontol. Geriatr. 43, 98-112. doi:10.1159/000504478

Michaloglou, C., Vredeveld, L. C. W., Soengas, M. S., Denoyelle, C., Kuilman, T., van der Horst, C. M. A. M., et al. (2005). BRAFE600-associated senescence-like cell cycle arrest of human naevi. Nature 436, 720-724. doi:10.1038/nature03890

Moro-Garcia, M. A., Alonso-Arias, R., and Lopez-Larrea, C. (2013). When aging reaches CD4+ T-cells: phenotypic and functional changes. Front. Immunol. 4, 107. doi:10.3389/fimmu.2013.00107

Nanda, A., Vura, N., and Gravenstein, S. (2020). COVID-19 in older adults. Aging Clin. Exp. Res. 32, 1199-1202. doi:10.1007/s40520-020-01581-5

Ouyang, Q., Wagner, W. M., Voehringer, D., Wikby, A., Klatt, T., Walter, S., et al. (2003). Age-associated accumulation of CMV-specific CD8+ T cells expressing the inhibitory killer cell lectin-like receptor G1 (KLRG1). Exp. Gerontol. 38, 911-920. doi:10.1016/s0531-5565(03)00134-7

Paget, J., Spreeuwenberg, P., Charu, V., Taylor, R. J., Iuliano, A. D., Bresee, J., et al. (2019). Global mortality associated with seasonal influenza epidemics: new burden estimates and predictors from the GLaMOR project. J. Glob. Health. 9, 020421. doi:10.7189/jogh.09.020421

Palacio, L., Goyer, M.-L., Maggiorani, D., Espinosa, A., Villeneuve, N., Bourbonnais, S., et al. (2019). Restored immune cell functions upon clearance of senescence in the irradiated splenic environment. Aging Cell. 18, e12971. doi:10.1111/acel.12971

Pawelec, G., and Gouttefangeas, C. (2006). T-cell dysregulation caused by chronic antigenic stress: the role of CMV in immunosenescence? Aging Clin. Exp. Res. 18, 171-173. doi:10.1007/BF0332743

Pawelec, G. (2014). Immunosenenescence: role of cytomegalovirus. Exp. Gerontol. 54, 1-5. doi:10.1016/j.exger.2013.11.010
Powell, T., Bellin, E., and Ehrlich, A. R. (2020). Older adults and covid-19: the most vulnerable, the hardest hit. Hastings Cent. Rep. 50, 61-63. doi:10.1002/ hast.1136

Thompson, H. L., Smithey, M. J., Surh, C. D., and Nikolich-Zugich, J. (2017). Functional and homeostatic impact of age-related changes in lymph node stroma. Front. Immunol. 8, 706. doi:10.3389/fimmu.2017.00706

Turner, V. M., and Mabbott, N. A. (2017). Influence of ageing on the microarchitecture of the spleen and lymph nodes. Biogerontology 18 , 723-738. doi:10.1007/s10522-017-9707-7

Vitale, G., Salvioli, S., and Franceschi, C. (2013). Oxidative stress and the ageing endocrine system. Nat. Rev. Endocrinol. 9, 228-240. doi:10.1038/nrendo.2013.29

Xu, M., Palmer, A. K., Ding, H., Weivoda, M. M., Pirtskhalava, T., White, T. A., et al. (2015). Targeting senescent cells enhances adipogenesis and metabolic function in old age. Elife 4, e12997. doi:10.7554/eLife.12997

Xu, M., Pirtskhalava, T., Farr, J.N., Weigand, B. M., Palmer, A.K., and Weivoda, M. M. (2018). Senolytics improve physical function and increase lifespan in old age. Nat. Med. 24, 1246-1256. doi:10.1038/s41591-018-0092-9

Zhu, Y., Armstrong, J. L., Tchkonia, T., and Kirkland, J. L. (2014). Cellular senescence and the senescent secretory phenotype in age-related chronic diseases. Curr. Opin. Clin. Nutr. Metab. Care. 17, 324-328. doi:10.1097/MCO.0000000000000065

Conflict of Interest: The author declares that the research was conducted in the absence of any commercial or financial relationships that could be construed as a potential conflict of interest.

Copyright (C) 2020 Haynes. This is an open-access article distributed under the terms of the Creative Commons Attribution License (CC BY). The use, distribution or reproduction in other forums is permitted, provided the original author(s) and the copyright owner(s) are credited and that the original publication in this journal is cited, in accordance with accepted academic practice. No use, distribution or reproduction is permitted which does not comply with these terms. 